\title{
Implementation of Digital Mammogram CAD Algorithm
}

\author{
Byungchea Lee*, Guirack Choi*, Jaeeun Jung ${ }^{* * *}$, Sangbock Lee \\ Dept. of Radiology, Nambu University ${ }^{*}$ Education Academy of Radiation ${ }^{* *}$, \\ Dept. of Radiological Science, Daegu Health College ${ }^{* * *}$

\section{디지털 유방영상의 $\mathrm{CAD}$ 알고리즘 구현} \\ 이병채*, 최규락**, 정재은**, 이상복* \\ 남부대학교 방사선학과*, 방사선교육아카데미**, 대구보건대학교 방사선과***
}

\begin{abstract}
Medical imaging has increased rapidly in the increase of interest in health, with the development of computer technology, digitization of medical imaging is rapidly advancing, PACS has been introduced to the medical field. Increase in the production of medical images by these phenomena made increased the workload of radiologist who must read a medical image. in response to the need for secondary diagnosis using a computer, The term of $\mathrm{CAD}$ in medical radiology field was introduced. In this study, we have proposed a $\mathrm{CAD}$ algorithm for the interpretation of the image obtained by the digital X-ray mammography equipment. The experiments were performed by programmed in Visual $\mathrm{C}++$ for the proposed algorithm. A result of the execution of the CAD algorithm seven sample images, the results of five samples was confirmed in breast cancer and benign tumors, both the images sample was error processing. If you use a program that implements this with the algorithm proposed in this study it is helpful to reading breast images, and it is considered to contribute significantly to the early detection of breast cancer.
\end{abstract}

Key words: Digital Mammography, Digital Mammogram, Algorithm

\section{요 약}

건강에 대한 관심의 증대로 의료영상이 빠르게 증가하고 있으며, 컴퓨터 기술의 발전으로 의료영상의 디지털화가 빠르게 진전되어 PACS가 의료현장에 도입되었다. 이러한 현상에 의한 의료영상 생산의 증가는 의료영상을 판독하여 야 하는 영상의학과 전문의의 업무량을 증가하게 하였다. 이러한 추세에 따라 컴퓨터를 이용한 보조 진단의 필요성이 대두되어 의료영상 판독 분야에 $\mathrm{CAD}$ 라는 용어가 생겨나게 되었다. 본 연구에서는 디지털 $\mathrm{X}$-선 유방촬영장치에 의하 여 획득된 영상의 판독을 위한 $\mathrm{CAD}$ 알고리즘을 제안하였다. 제안된 알고리즘을 Visual $\mathrm{C}++$ 로 프로그램하여 실험하 였다. 본 연구에 사용한 일곱 샘플영상을 $\mathrm{CAD}$ 알고리즘으로 실행한 결과 다섯 샘플의 결과는 양성종양 및 유방암으로 확인되었고 두 샘플 영상은 error처리 되었다. 본 연구에서 제시한 알고리즘과 이를 구현한 프로그램을 이용한다면 판 독업무에 많은 도움이 될 것이며, 유방암의 조기발견에 크게 기여할 것으로 사료된다.

중심단어: 디지털 유방촬영술, 디지털 유방영상, 알고리즘 


\section{I. 서 론}

병원정보시스템(hospital information system)의 발전 과 의료영상저장 및 전송시스템(picture archiving and communication system)의 발전으로 의료정보가 매우 빠 르게 증가하고 있다[1]. 이러한 추세에 따라 의료영상의 생산도 빠르게 증가하여 의료영상을 판독하여야 하는 영상의학과 전문의의 업무량이 폭주하고 있다 ${ }^{[2]}$. 이러 한 추세에 따라 컴퓨터를 이용한 보조 진단의 필요성 이 대두되어 의료영상 판독 분야에 $\mathrm{CAD}$ 라는 용어가 생겨나게 되었다 ${ }^{[3]}$. 또한 의료영상의 디지털화 기술의 발전으로 새로운 방사선의 검출기술이 발전함으로써 의료영상은 급격하게 디지털화하는 추세이다.

$\mathrm{CAD}$ 는 의사들의 지식이 컴퓨터로 구현되는 것으 로, 뮤어의 법칙에 기반한 컴퓨터 계산능력의 지속적 인 증가와 인터넷으로 대변되는 네트워킹 파워의 증 가로 정보통신이 하루가 다르게 발전하면서 현실적으 로 가능하게된 것이다 ${ }^{[4]}$. $\mathrm{CAD}$ 는 컴퓨터가 정량적으로 분석한 결과를 토대로 의료영상에서 이상이 있는 부 위를 표시함으로서 영상의학과 전문의의 과다한 판독 업무에 도움을 주며 이상이 있는 영상에 대하여 정량 적인 분석결과를 참고로 의사가 최종판단을 내리게 하는 진단보조 시스템이다.

이와 같은 $\mathrm{CAD}$ 시스템이 개발되면, 현재 의사의 육 안적인 인식과 판단능력의 한계로 인해 피할 수 없었 던 진단의 불확실성이 상당히 개선될 수 있으며, 폐암 이나 유방암의 조기 발견을 위한 스크리닝 사업에 따 르는 국가적인 의료비용을 대폭 경감할 수 있어 향후 의료기술의 중대한 진전이 될 것으로 판단되며, 이에 따른 상당한 새로운 시장의 형성도 기대된다[5].

유방암의 발견과 검진을 위한 가장 기본적인 방법 은 X선 촬영, 즉 mammography이다. 특히 유방 조직이 치밀하면 할수록, 다시 말해서 유선 조직이 많고 지방 이 덜한 사람의 경우, 방사선 투과성이 약해지기 때문 에 효과가 떨어진다. 반면에 치밀한 유방 조직일수록 여성의 유방암 발병 위험은 최대 5 배 증가하는 것으로 조사되었다 ${ }^{[6]}$.

초음파 유방영상은 유방병변의 특성을 파악하기 위 한 오랫동안 사용된 검사방법이다. 초음파는 전리방사
선이 아닌 고주파 음파를 사용하기 때문에 조직의 밀 도는 크게 문제가 되지 않는다. 초음파를 이용하면 비 정상 조직이 부드러운지 또는 딱딱한지를 알 수 있게 된다 ${ }^{[6]}$.

본 연구에서는 디지털 $\mathrm{X}$ 선 유방촬영장치에 의하여 획득된 영상의 판독을 위한 $\mathrm{CAD}$ 프로그램 알고리즘 을 제안하려고 한다.

\section{II. 이론적 배경}

\section{1. 소벨(Sobel)마스크를 이용한 윤곽선 검출 알고리즘}

윤곽선이란 영상 안에서의 영역의 경계부분을 나타내는 특징으로 픽셀 밝기의 불연속점을 나타 낸다. 윤곽선은 영상 내에 있는 물체의 윤곽에 대 응되며 많은 정보를 가지고 있는 물체의 위치, 모 양, 크기, 표면의 무늬 등에 대한 정보를 알려주는 역할을 한다. 흔히 보는 물체의 정보, 즉 물체가 어 떻게 생겼는가는 그 물체의 안쪽 면을 보는 것은 아니고 그렇다고 물체의 바깥 면만 보는 것도 아니 다. 사람은 눈은 물체의 안쪽 면과 물체의 바깥쪽 면의 경계를 보고 물체를 식별하게 된다. 이렇게 인식할 수 있는 것은 빛의 반사정도가 물체와 배경 과의 경계를 사이에 두고 밝기 차가 눈에 띄게 나 타나기 때문이다. 이 밝기의 차로 인간은 물체를 인식하여 구분하게 된다. 윤곽선은 영상 내에서 상당한 밝기 차이가 있는 곳이고 이것은 대개 물체 의 경계에 해당하는 곳이므로 대개 픽셀값의 불연 속이나 픽셀 미분값의 불연속 점에 존재한다 ${ }^{[7]}$. 따라서 영상 안에서 불연속점은 Table 1 과 같이 분류할 수 있다.

Table 1. Classification of discontinuities in images 스텝 불연속 점(Step Edge) : 영상의 밝기가 갑자기 변화하는 점 라인 불연속 점(Line Edge) :

영상의 밝기가 갑자기 변화하나 조금 지나면 다시 돌아오는 점 
윤곽선 검출은 영상처리 기법에서 간단하면서도 유 용한 방법으로 응용분야 또한 매우 넓다. 예를 들면 윤곽선 검출로 경계가 강조된 영상을 얻어 의학영상 에서 진단에 도움을 줄 수 있고 의학영상의 특징을 추 출하는 방법으로도 사용할 수 있다.

\section{Table 2. Edge Detection Method}

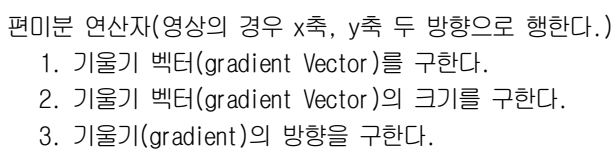

연산 방법은 입력영상 안의 픽셀들을 마스크의 동 일 위치에 해당하는 픽셀들과 곱하고 모든 픽셀을 더 하여 중심 픽셀에 할당하면 된다. 윤곽선 검출의 가장 대표적인 미분연산자인 소벨 마스크는 Table 3 과 같은 특징을 가지고 있다 ${ }^{[8]}$.

\section{Table 3. Sobel mask Features}

2 차 미분연산자이며 $x$ 축, $y$ 축으로 각각 한번씩 미분한다. 소벨 마스크(왼쪽:Gx미분연산자, 오른쪽:Gy미분연산자)

기울기의 크기는 $G=\sqrt{G x^{2}+G y^{2}}$ 이다.

(단, $G x: x$ 축 편미분, $G y: y$ 축편 미분) 프로그램의 간결성을 위하여 기울기를 " $G=|G x|+|G y| Z$ ” 로 사용하기도 한다.

윤곽선 검출을 위한 Sobel 연산을 위한 알고리즘은 Fig. 1 과 같다 ${ }^{[9]}$.

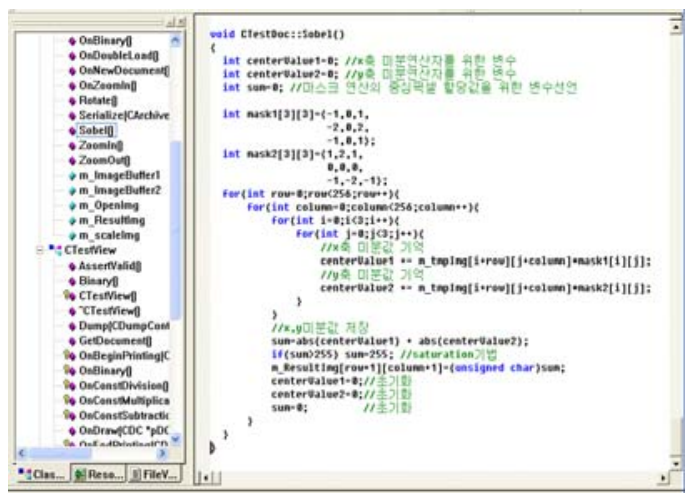

Fig. 1. Sobel operation algorithm.

\section{2. 유방영상 질환부위의 분할}

영상 분할(image segmentation)이란 영상을 밝기, 색 상, 텍스처, 모션 등의 특징값이 유사한 영역으로 나 누는 것을 의미한다 ${ }^{[9]}$. 일반적으로 영상 내에 존재하 는 특정 객체를 인식하거나 분석하기 위해서는 그 객 체의 영역만을 정확하게 추출할 필요가 있기 때문에 영상 분할은 여러 영상 처리 분야의 기초적인 연구로 써 진행되고 있다. 최근에는 동영상에서 움직임 정보 를 이용하여 움직임이 있는 객체와 배경을 분리하는 형태의 영상 분할에 관한 연구도 활발히 진행되고 있 다 ${ }^{[10]}$.

일반적인 자연 영상을 분할하는 방법으로 mean-shift 를 이용한 방법과 watershed 알고리즘을 이용한 방법이 존재한다. Mean-shift 란 특정 데이터의 근방에 존재하 는 주변 데이터들의 평균쪽으로 중심을 이동시키면서 유사한 데이터를 군집화하는 알고리즘이다 ${ }^{[11]}$.

Comaniciu는 자연 영상에서 추출한 색상들을 mean-shift 알고리즘을 이용하여 군집화하여 동일한 색 상의 영역을 병합하는 알고리즘을 제안하였다 ${ }^{[12][13]}$. 이 방법은 색상의 구분이 확실한 영상에 대하여 매우 우수한 성능을 보여준다. Watershed 알고리즘은 영상 의 그래디언트(gradient) 정보를 이용하여 영역을 구분 하는 방법이다 ${ }^{[14]}$. 이 방법은 자연 영상과 그레이스케 일(gray-scale) 영상에 모두 적용할 수 있는 방법이지만, 약간의 잡음(noise)에 의해 영역이 과분할될 수 있다는 단점이 있다. Fig. 2는 영상분할 알고리즘을 나타내고 있다.

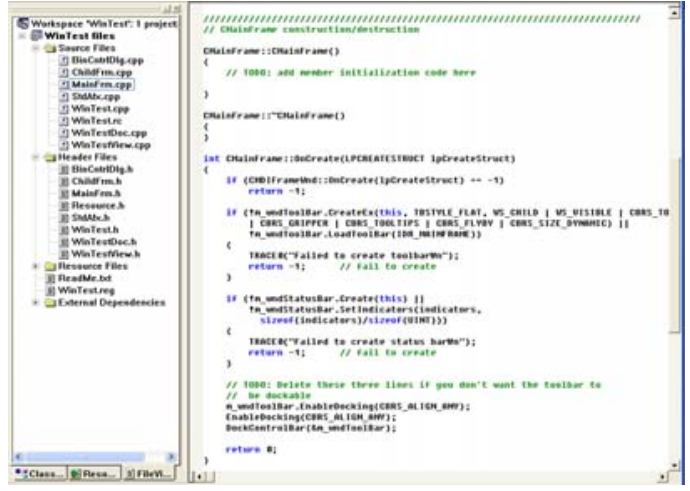

Fig. 2. Image Segmentation Algorithm. 


\section{III. 실험 및 방법}

본 연구를 위한 실험 절차는 Fig. 3과 같이 실시하였다.

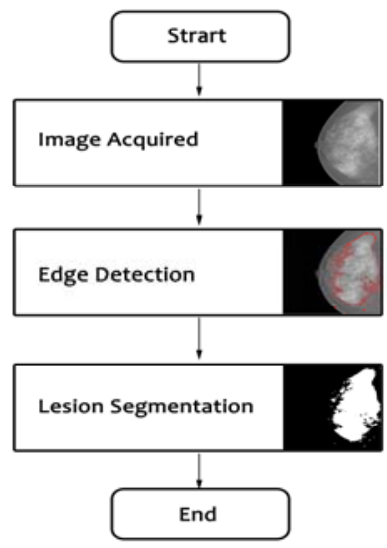

Fig. 3. Experimental procedures.

\section{1. 영상획득}

촬영에 활용한 디지털 유방촬영장치는 Fig. 4에 나 타내었으며, 촬영하여 획득된 영상을 Fig. 5에 나타내 었다.
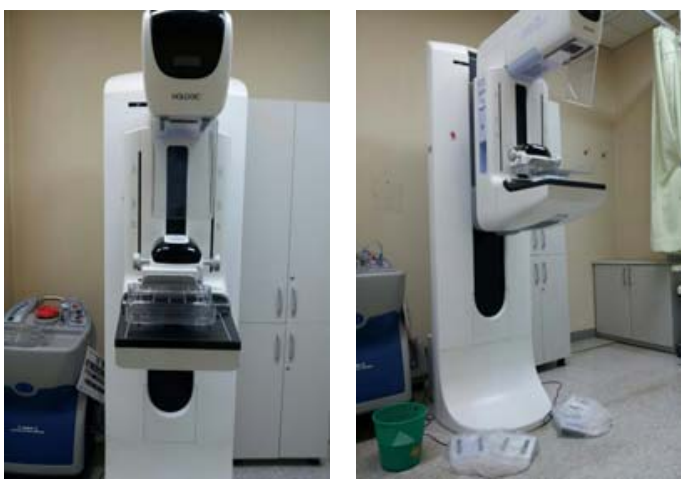

Fig. 4. Mammography Equipment.

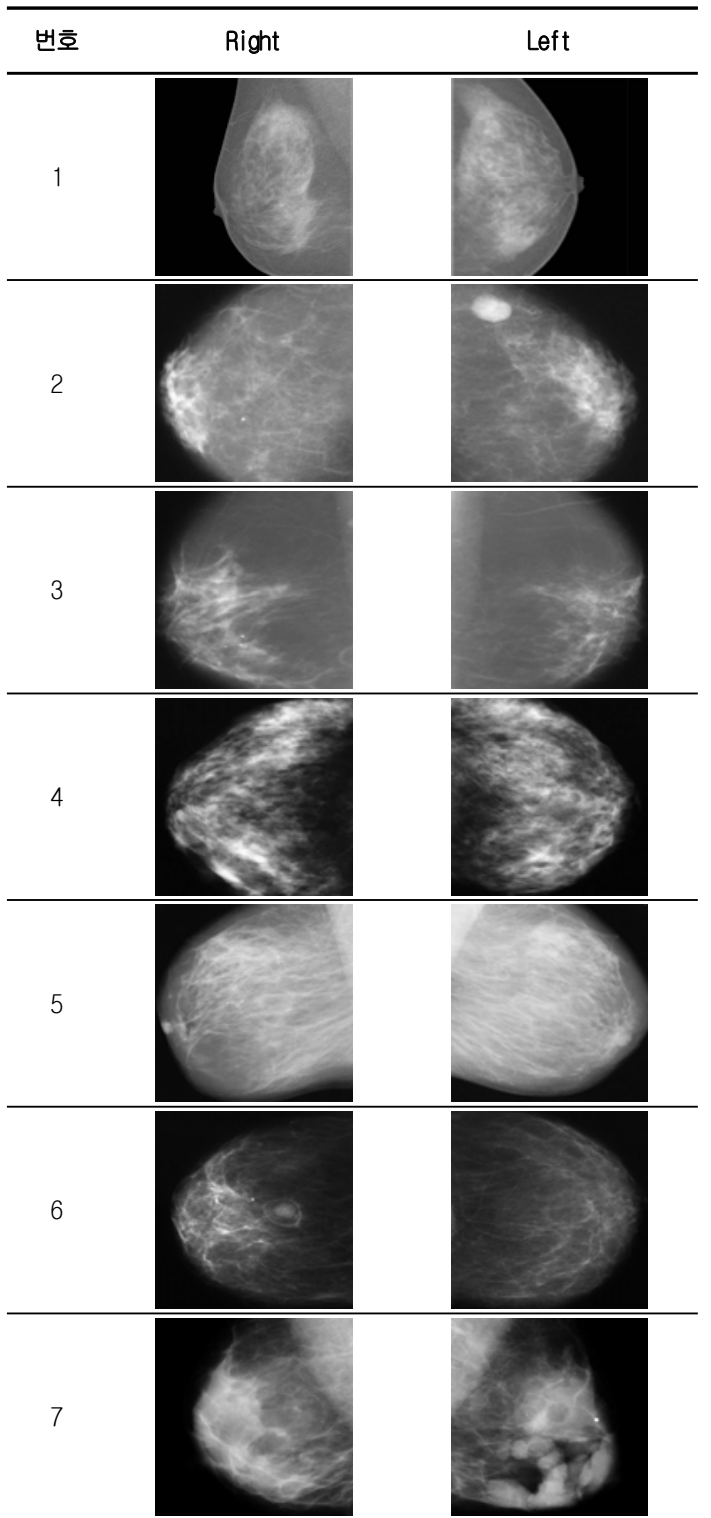

Fig. 5. Acquired images.

획득된 영상은 경계선 검출과 영상 분할, 그리고 이 진화 알고리즘을 C 언어로 구현한 Fig. 6의 프로그램 에 입력하여 실험하였다. 


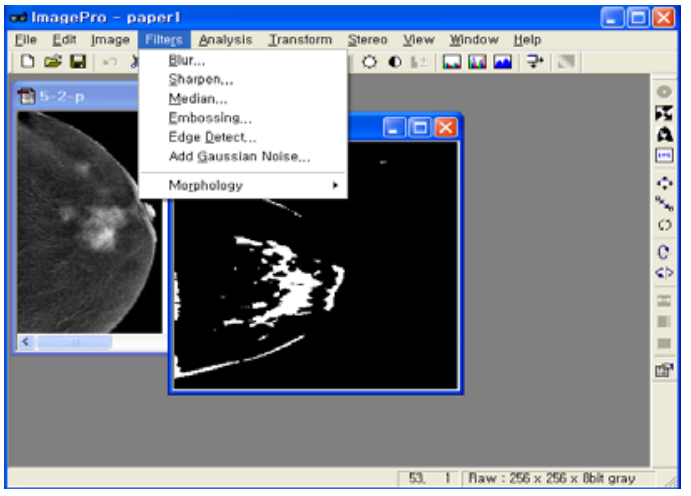

Fig. 6. Experiments using the implemented program.

\section{Sobel 연산자를 이용한 경계선 검출}

Fig. 5와 같이 획득한 디지털 유방영상을 Fig. 6의 프 로그램에 입력하여 Fig. 7과 같이 경계선을 검출하였다. 경계선 검출 알고리즘은 소벨 연산자를 사용하였다.

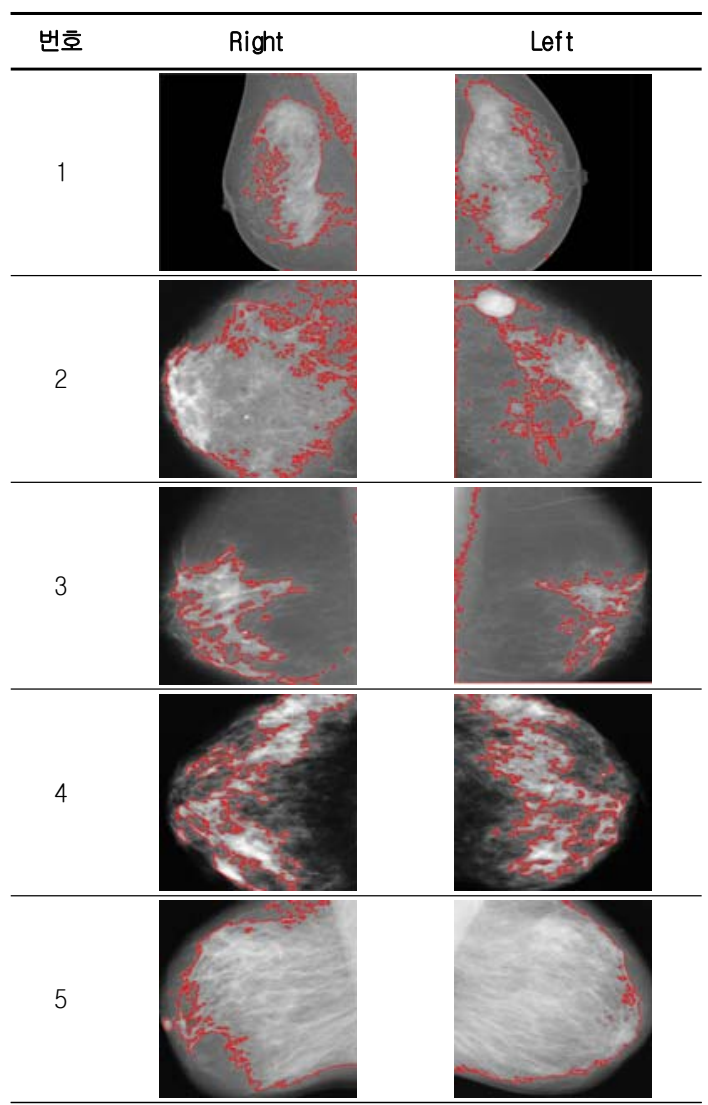

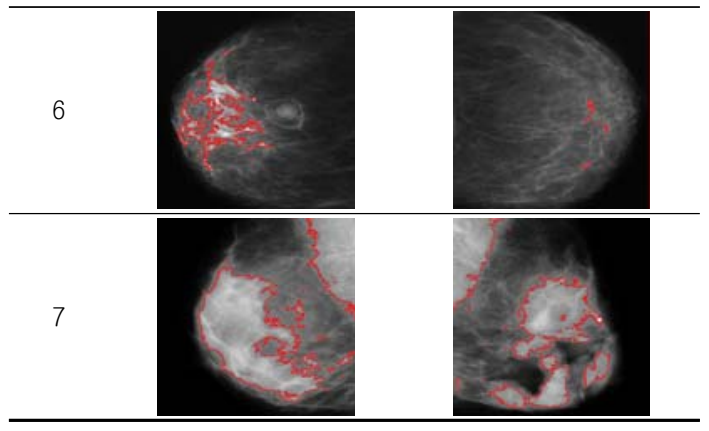

Fig. 7. Edge Detection images.

\section{3. 질환부위 분할}

Fig. 7과 같이 경계선이 검출된 영상을 저장한 후, Fig. 6의 프로그램에 읽어 들여 Fig. 8과 같이 질병 부 위를 분할하였다.

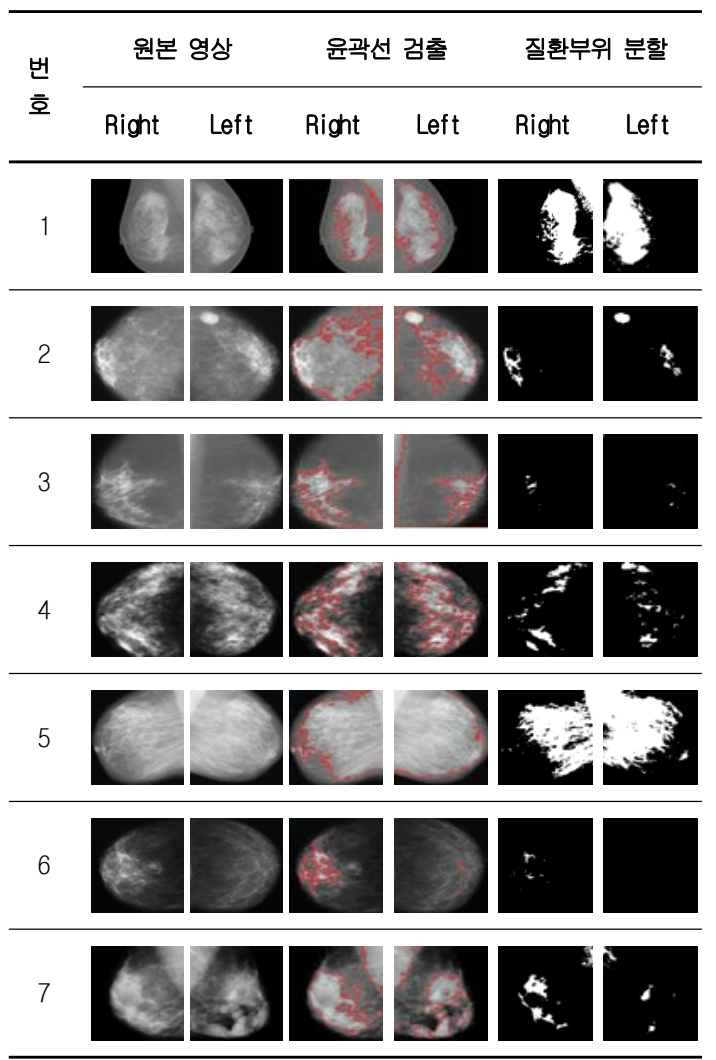

Fig. 8. Lesion segmentation images.

Fig. 8에 보여지는 분할된 영상의 모양과 Fig. 9에 제 공되는 유방종괴 형태학적 스펙트럼과 비교하여 유방 
암의 여부를 판단을 하였다.

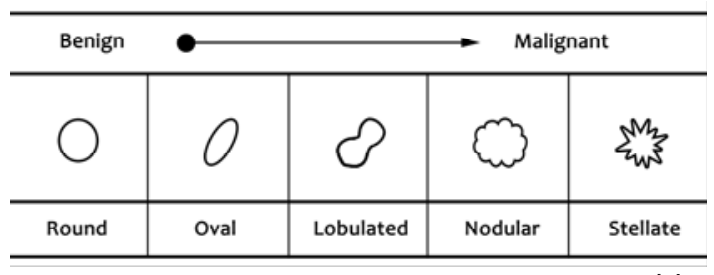

Fig. 9. Morphologic spectrum of mammographic masses ${ }^{[15]}$.

\section{$\mathrm{IV}$. 결과}

일곱 샘플의 유방영상을 입력하여 실험한 결과 Fig. 10 과 같은 결과를 얻을 수 있었다.

\begin{tabular}{|c|c|c|c|c|c|}
\hline 순번 & Right & Left & Decision & $\begin{array}{c}\text { right or } \\
\text { error }\end{array}$ & $\begin{array}{c}\text { Thresh } \\
\text { old }\end{array}$ \\
\hline 1 & & & Cancer & right & 158 \\
\hline 2 & & & Cancer & right & 178 \\
\hline 3 & 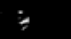 & & Cancer & right & 178 \\
\hline 4 & & & Cancer & right & 178 \\
\hline 5 & & & Benign & error & 178 \\
\hline 6 & : & & Benign & error & 178 \\
\hline 7 & & & $\begin{array}{c}\text { Hamar- } \\
\text { toma }\end{array}$ & right & 178 \\
\hline
\end{tabular}

Fig. 10. Results of Experiment.

위 영상은 영상의학과 전문의에게 판독을 의뢰한 결과 모두 양성종양 및 유방암으로 판독된 영상이다. $\mathrm{CAD}$ 프로그램을 통하여 확인한 결과 두 영상은 error 처리 되었으며, 나머지 영상은 유방암 및 과오종으로 인식되었다. 구체적으로 질환 부위 분할 영상에서 실 험한 결과는 다음과 같다.

실험영상 1 의 경우는 임계값은 158 로 하였으며, 유
방암으로 판단되었다. 실험영상 2의 경우도 임계값은 178 로 하였으며, 유방암으로 판단되었다. 실험영상 3 의 경우도 임계값은 178 로 하였으며, 유방암으로 판단되 었다. 실험영상 4 의 경우도 임계값은 178 로 하였으며, 유방암으로 판단되었다. 실험영상 5 의 경우 윤곽선 검 출, 질환부위 분할의 결과 error처리 되었다. 이는 질환 이 유방암이 아니며, 모양이 너무나 다각적이고, 광범 위하게 나타난 이유이다. 실험영상 6의 경우 윤곽선 검출, 질환부위 분할의 결과 error처리 되었다. 이는 질 환이 유방암이 아니며, 모양이 너무나 미소하고, 정보 량이 부족한 이유이다. 실험영상 7의 경우는 임계값은 178 로 하였으며, 과오종으로 판단되었다.

\section{$\mathrm{V}$. 고찰 및 결론}

본 연구에서는 디지털 X-선 유방촬영장치에 의하여 획득된 영상의 자동판독을 위한 $\mathrm{CAD}$ 알고리즘을 구 현하였다. 구현한 프로그램을 통하여 확인한 결과 실 험영상 1 의 경우는 임계값은 158 로 하였으며, 실험영 상 $2 \cdot 3 \cdot 4$ 의 경우는 임계값을 178 로 하였고, 네 영상 모두 유방암으로 판단되었다. 실험영상 $5 \cdot 6$ 의 경우는 윤곽선 검출, 질환부위 분할의 결과 error처리 되었다. 이는 두 영상 모두 질환이 유방암이 아니며, 실험영상 5 는 모양이 너무나 다각적이고, 광범위하게 나타난 이 유이고, 실험영상 6 은 모양이 너무나 미소하고, 정보량 이 부족한 이유이다. 실험영상 7 의 경우는 임계값은 178 로 하였으며, 과오종으로 판단되었다.

구현한 프로그램을 이용하여 유방영상 판독을 실시 한다면 영상의학과 판독의 들의 판독 전·후 과정상 에 $\mathrm{CAD}$ 프로그램을 통한 결과가 판독에 도움이 될 것 이다. 이는 정확한 판독을 돕고 판독 전 기초적 정보 를 제시하는데 충분할 것이다.

그러나 국내의 의료환경에서는 아직까지 $\mathrm{CAD}$ 프로 그램의 적용이 판독과정에서 현실적으로 확대 보급되 지 않은 실정이다. 이는 보수적이고 전통적인 의료환 경에 익숙한 의료인의 관점 문제와 현행 법률에서 뒷 받침 되지 못하고 있는 현실의 문제가 크다고 할 수 있다.

$\mathrm{CAD}$ 알고리즘과 같은 자동판독 시스템의 도입을 위하여 의료법의 제도적 정비와 영상의학과 전문의들 
의 협조가 선행되어야 할 문제로 사료된다.

\section{참고문헌}

[1] M.E. Ahn, G.H. Choi, "A Develop mental Process of Telemedicine, e-Health \& u-Health", J Korean Med Assoc, Vol. 52, No. 12, pp. 1131-1140, 2009.

[2] J.H. Lim, W.S. Park, J. M. Ahn, S.S. Kim, H. Cheung, H.S. Choi, "Cost Benefit of PACS", JKSIIM, No. 6, pp. 9-18, 2000.

[3] L.J. Koo, I.S. Jung, J.H. Bea, S.W. Choi, H.B. Park, G.N. Wang, "The Proposal of Segmentation Algorithm for the Applying Breast Ultrasound Image to CAD", IE interfaces, Vol. 21, No. 4, pp. 394 402, 2001.

[4] J.S. Hwang, "u-Korea Strategy for the ubiquitous intelligent society", Telecommunications Review, Vol. 15, No. 1, pp. 15 23, 2005.

[5] S.C. Park, M.E. Lee, S. H. Kim, I.S. Na, Y.J Chen, "Machine Learning for Medical Image Analysis", jkiise, Vol. 39, No. 3, pp. 163 174, 2012.

[6] Boyd N.F., Guo H., Martin L.J., Sun L., Stone J., Fishell E., Jong R.A., Hislop G., Chiarelli A., Minkin S., Yaffe M.J., "Mammographic Density and the Risk and Detection of Breast Cancer." New England Journal of Medicine. Vol. 356, pp. 227-236, 2007.

[7] J.H. Kim, D.S. Noh, "Vehicle License Plate Recognition System By Edge-based Segment Image Generation", JKCA, Vol. 12, No. 3, pp. 9 16, 2012.

[8] G.R, Choi, J,H, Lee, "Edge Detection of Sonogram Using Sobel Operator", Journal of the Korean Society of Radiology, Vol. 2, No. 2, pp. 17 21, 2008.

[9] M. Sonka, V. Hlavac, R. Boyle, "Image processing, analysis, and machine vision", PWS publishing 2nded, 1998.

[10] Y. Tsaig, A. Averbuch, "Automatic segmentation of moving objects in video sequences: A region labeling approach", IEEE Trans. Circuits and Systems for Video Technology, Vol. 12, No. 7, pp. 597-612, 2002.

[11] Y. Cheng, "Mean shift, mode seeking, and clustering", IEEE Trans. Pattern Anal. Machine Intell., Vol. 17, No. 8, pp. 790-799, 1995.

[12] D. Comaniciu, P. Meer, "Mean Shift: A Robust Approach toward Feature Space Analysis", IEEE Trans .Pattern Anal. Machine Intell., Vol. 24, No. 5, pp. 603-619, 2002.

[13] D. Comaniciu, P. Meer, "Robust analysis of feature spaces: color image segmentation" Computer Vision and Pattern
Recognition, pp. 750-755, 2002.

[14] L. Vincent, P. Soille, "Watershed in digital spaces: An efficient algorithm based on immersion simulations" IEEE Trans .Pattern Anal. Machine Intell., Vol. 13, No. 6, pp. 583-598, 1991.

[15] Céelia Freitas da Cruz, "Automatic Analysis of Mammography Images", Master in Biomedical Engineering, Porto University, 2011. 